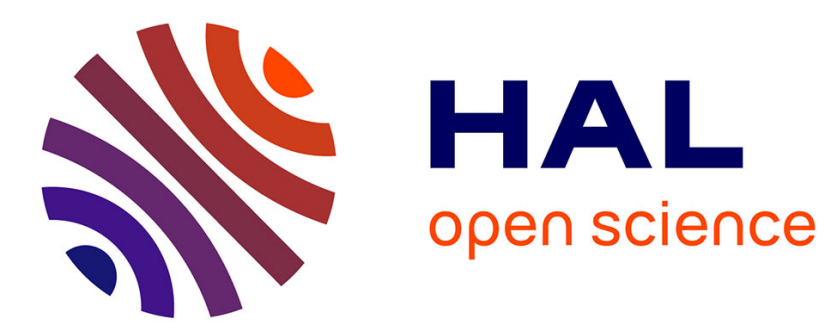

\title{
Incorporating Adult Learning Principles in High-Risk Equipment Operations Training
}

\author{
Richard Skiba
}

\section{To cite this version:}

Richard Skiba. Incorporating Adult Learning Principles in High-Risk Equipment Operations Training. International Education Studies, 2020, 13 (10), pp.60. 10.5539/ies.v13n10p60 . halshs-02955579

\section{HAL Id: halshs-02955579 \\ https://shs.hal.science/halshs-02955579}

Submitted on 2 Oct 2020

HAL is a multi-disciplinary open access archive for the deposit and dissemination of scientific research documents, whether they are published or not. The documents may come from teaching and research institutions in France or abroad, or from public or private research centers.
L'archive ouverte pluridisciplinaire HAL, est destinée au dépôt et à la diffusion de documents scientifiques de niveau recherche, publiés ou non, émanant des établissements d'enseignement et de recherche français ou étrangers, des laboratoires publics ou privés. 


\title{
Incorporating Adult Learning Principles in High-Risk Equipment Operations Training
}

\author{
Richard Skiba ${ }^{1}$ \\ ${ }^{1}$ LRES Training Management, Melbourne, Australia \\ Correspondence: Richard Skiba, LRES Training Management, Melbourne, Australia. E-mail: \\ richard@skiba.com.au
}

Received: April 30, 2020

Accepted: July 2, 2020

Online Published: September 21, 2020

doi:10.5539/ies.v13n10p60

URL: https://doi.org/10.5539/ies.v13n10p60

\begin{abstract}
This paper, primarily based on a literature review, considers the utilization of adult learning principles in training learners to operate high risk equipment. Vocational Education and Training sectors throughout the world are traditionally responsible for training delivery in these areas where generally andragogical principles as defined by Knowles (1970), are applied with, in some cases, application of a heutagogical approach, as outlined by Hase and Kenyon (2000). Aside from considering these approaches, a new approach is proposed, referred to as authology, with a basis of including notions of responsibility and duty of care in adult learning.

There are numerous training programs in vocational education and training, such as those related to high risk equipment and plant operation, for which development of learner responsibility is a critical component in the training given the potential to cause harm, injury or fatality.
\end{abstract}

Keywords: adult learning principles, vocational education, high risk work, training practices, learning styles

\section{Introduction}

Adult Learning Australia (2020) outlines that Alexander Kapp and Eugen Rosenstock-Huessy formed theories around adult education, which were later extended by Malcolm Knowles. Mowson (2018) further illuminates Malcolm Knowles defined the term 'andragogy' in the 1970's as referring to methods and principles used in adult education. Knowles (1970) used term 'andragogy' to explain the art and science of helping adults to learn. In 1984, Knowles identified six adult learning principles including: The need to know; Self-concept; Experience; Readiness to learn; Orientation to learning; and Motivation. These learning principles established a platform for training practices beyond the basic provision of instruction and are especially applicable to vocational education and training where a main goal is to develop job ready workers.

Knowles (1990) outlines that an andragogical approach is advocated as a way of facilitating more meaningful outcomes for learners. Within vocational education and training, there is evidence of use of an andragogical approach based on provision of flexible delivery, supporting the notion of learners as individuals in a specific or particular context, and on the basis that learners are required to take responsibility for their own learning (Choy \& Delahaye, 2002).

The concept of andragogy then can emphasize the value of the process of learning. Watson (2015) elaborates that andragogy uses approaches to learning that are problem-based and collaborative rather than instructive, and also underscores equality between the teacher and learner. Trainers, on this basis facilitate a learners' progression toward self-directed and responsible learning, whilst fostering the learner's internal motivation to learn. Adult Learning Australia (2020) outlines that motivation can be reduced by where learning experiences do not encompass adult learning principles. Inclusion of adult learning principles in training practices strengthens the outcome of the learning such that knowledge and skills are better retained which is fundamental to producing workers who will engage in their workplaces not only effectively, but also safely.

Applying andragogical principles to technical education elicits any number of best practices in training provision. These include giving learners the opportunity to use the knowledge and experience that they have acquired and to apply these to new learning events and scenarios (Watson, 2015). Watson also notes that adult learners are ready to learn when they experience a need to learn to better cope with real-life tasks or problems (Knowles, 1980, p. 44, as cited in Fidishun, 2000). Trainers, then, are in a position to, through application of andragogical principles, enable 
a learner's readiness for problem-based learning and improve the learner's awareness of the need for the knowledge or skill being developed through the training activity.

Another adult learning principle in vocational education and training is that of the relevancy orientation of adults. Adult learners have a desire to appreciate the relevance of what they are learning to what they want to accomplish (Watson 2015).

Given that adults learn through direct experience, their training and learning activities should include active and practical participation and provide a range of usable and functional techniques and practices that can improve their everyday lives, whether in or out of a workplace context.

Heutagogy is another learning principle worthy of consideration. Hase and Kenyon (2000) surmise that heutagogy is the study of self-determined learning and noting the approach is an attempt to challenge some ideas about teaching and learning. The approach is presented as an extension to andragogical approaches as described by Knowles. Heutagogy considers knowing how to learn as a fundamental skill, particularly necessary with innovation and change common in workplace environments and communities. This premise highlights the need for adaptability in the workplace, a skill that can be developed during training. Hase and Kenyon submit that a heutagogical approach recognises that learners need flexible in their learning. Flexibility in this case refers to a trainer providing resources and the learner designing the actual course he or she might take by negotiating the learning, essentially with the trainer acting as a facilitator and the learner providing a degree of control over the course of the learning. This principle advocates that trainers should concern themselves with developing the learner's capability, rather than just embedding discipline-based skills and knowledge (Hase \& Kenyon, 2000).

Blaschke (2012) informs that competent learners demonstrate the acquisition of knowledge and skills and the acquired skills can be repeated and knowledge that can be retrieved. The knowledge and skills are not only replicable and repeatable but can also be applied to a range of contexts, such as is required in any work environment. Capable learners are able to reproduce knowledge and skills in unfamiliar situations. Blaschke (2012) states that capability can be seen as an extension of one's own competence, noting that without competency there cannot be capability. A heutagogical approach condones development of capability beyond competence. Learners are able to increase their awareness of their preferred learning style and are able to recognise these in context and thus adapt new learning situations to their learning styles, and in turn, making them more capable learners.

With a focus on both competency and capability, heutagogy moves trainers a step closer toward better addressing the needs of adult learners in complex and changing work environments (Bhoryrub et al., 2010, cited in Blaschke, 2012). The incorporation of heutagogical practice presents an opportunity for trainers to effectively prepare learners for the workplace and for becoming lifelong learners. Heutagogical practice foster learner motivation by cultivating learners who "are fully engaged in the topic they are studying because they are making choices that are most relevant or interesting to them" (Kenyon \& Hase, 2010, p. 170, cited in Blaschke, 2012). As such, the heutological approach is associated with self-determined learning. The learner is central to the process and the trainer acts a mentor to facilitate the learning. Learning in this environment allows a learner to synthesize new knowledge through utilization of reflective and critical thinking skills.

Davis (2018) summarizes that whereas pedagogy is teacher-led learning and andragogy is self-directed learning, heutagogy takes an approach that is different to both approaches. This notion is on the basis that a heutagogical approach is self-determined learning. In pedagogical environments, trainers determine what learners will learn and how they will learn it. Davis outlines that learners rely on their trainer and learn topics in the order in which they are presented, as established by the trainer. She contrasts that learners use the trainer as a mentor or guide in andragogical environments, with learners aiming to discover their own solutions to the tasks the trainer sets. The heutagogical approach encourages learners to uncover their own problems and questions to solve. In this case, rather than undertaking and completing tasks assigned by the trainer, the learners seek out areas of uncertainty and complexity in the subjects they examine. Trainers help by providing context to learners' learning and create opportunities for them to explore subjects fully. Learners are given the opportunity to be included in the assessment design process, within constructs set by the trainer, and an opportunity to reflect on their experiences. The learners, through shared communities inclusive of resources and knowledge, develop shared meanings by working together, as is reflective of workplace processes.

In many adult training scenarios, learners may not be highly autonomous and self-directed initially. However, their approach to learning progresses and matures as they progress in skill and life. Davis (2018) suggests that pedagogical oriented teaching is predominantly used in training basic skills as a foundation for forthcoming experiences whereas for andragogical oriented training, the goal is to create some structure such that learners can 
be self-directed. Davis notes that for heutagogical oriented training, the purpose is to create a learning environment in which learners can determine their own goals, learning paths, processes, and products. She outlines that when applying heutagogical approach, the learner transitions from passive recipient to analyst and synthesizer. These abilities may be considered as some of the most valuable skills for learners interacting with a world requiring knowledge management and curation (Davis, 2018). A consideration of these learning principles, and an understanding of adult learning principles by trainers, is essential in an adult learning environment focused on training related to high risk occupations or use of high-risk equipment.

\section{Method}

The discussion and conclusions drawn are based on a literature review together with consideration of the current adult learning principles in vocational education training and assessment. This paper outlines the application of these adult learning principles within a specific context, where training and assessment is related to high risk plant and equipment operations. The discussion firstly establishes where current approaches based on accepted adult leaning principles fit into the training repertoire and then examines aspects of high-risk work that may not be effectively addressed. An additional approach that should be integrated into training activities is then considered, particularly from the perspective of establishing a greater sense of responsibility and meeting duty of care obligations.

\section{Discussion}

\subsection{Significance of Adult Learning Principles}

Collins (2004) identifies that the teaching approach should be based on the objective of the teaching-learning situation and believes that the learner-centered andragogic may not be appropriate in all adult education settings, as supported by Imel (2004), cited in Collins (2004). Collins notes that the training approach should be based on the objectives of the learners, the training content, and may include other factors. As such, Collins identifies that selection of one training approach may not be suitable for all training scenarios.

There are several related and relevant themes presented by Collins (2004) to be considered. The first of these is the notion that the learner should be actively involved in learning and should be encouraged to be active. This entails provision of the opportunity to practice new behaviour in a safe and supportive environment.

To outline the value of active participation Collins (2004) refers to Rogers (1969) who distinguished two types of learning, referred to as cognitive and experiential. Collins outlines that cognitive learning can be seen as academic knowledge, whereas experiential learning encapsulates learning by doing and notes that Rogers perceived the qualities of experiential learning as personal involvement, self-initiated, learner evaluated, and having a pervasive effects on the learner. Rogers (1969) ties into the concepts of andragogical principles with suggestions that significant learning can occur when the subject matter is perceived as having relevance for their own purposes by the learner, stating that "A somewhat more formal way of stating this is that a person learns significantly only those things which he perceives as being involved in the maintenance of or the enhancement of his own self" (p. 158).

Collins (2004) also introduces transference and suggests that transference occurs through association where a learner can associate newly acquired information with something they already know. This process occurs when the new information is similar to material the learner already knows, through, as identified by Collins, similarity. Associative learning essentially takes place through experience. The extent to which this occurs is related to the learner's degree of original learning. Collins (2004) notes that transference is greatest when the level of original learning is high and when the information being learned contains elements that are of extreme benefit to the learners' work environment. Again, these concepts tie in with the principles associated with andragogical approaches. There are then several key principles derived from andragogy and heutagogy that can be applied to training and, in turn, adult learning and their application should vary with the learning content, context and purpose.

Collins identifies that not all people learn in the same way and to engage all learners, methods by which information is communicated should be varied. In order to so, methods can include group discussion, role-playing, lecturing, case studies, games, questioning, and using varying technology. In doing so, a range of learning principles can be employed to maximize the effectiveness of the learning. Putting this into context, Collins (2004) outlines:

"Studies reveal that over a period of 3 days, the retention of learning is $10 \%$ of what we read, $20 \%$ of what we hear, $30 \%$ of what we see (demonstration), $50 \%$ of what we see and hear (discussion), $70 \%$ of what we say (practice), and $90 \%$ of what we say as we do (teach others, immediate use). It follows that an effective learning protocol is to watch one (demonstration), do one (practice), and 
teach one (use new learning)" (p. 1487).

These statements highlight the importance and significance of practical experience throughout learning experiences and putting learning into practice and confirm the role of experience in transference. Collins (2004) concludes that all theories of adult education are based on appreciating and applying a learner's prior learning and their experience and notes that "adult learning requires building on this prior learning, using methods that treat learners with respect, and recognizing that people have different learning styles and have a variety of responsibilities and time commitments" (p. 1489). Colins advises that the optimal role of the adult learner in the learning situation is one that is characterized by of a self-direction, self-motivation and collaboration in the learning process and is an individual who takes responsibility for learning.

\subsection{Adult Learning Styles}

Aside from adult learning principles, adult learning styles also warrant consideration when delivering training. Adult learning styles refer to learning approaches that learners naturally prefer to maximize their personal learning experience (Adult Learning Australia, 2020). Peter Honey and Alan Mumford, cited in Adult Learning Australia (2020) and based upon the work of Kolb, have identified four adult learning styles. These include Activists, Reflectors, Theorists and Pragmatists. Activists are those inclusive of learners who learn by doing, where Reflectors learn by observation and thinking about what happened. Theorists like to understand the theory behind the actions and Pragmatists are those who need to be able to see how to put the learning into practice in the real world.

Activists can benefit from learning activities such as brainstorming, practical experimentation, role plays, group discussion and problem-solving. Pragmatist activities include case studies and use of activities that provide time to think about the practical applications the learning. Reflector-style learning includes spending time reading about a subject, and observing others experimenting. Theorist learning entails exposure to models and theories, with access to high levels of background information (Skills You Need, 2020). Knowing that there are different learning styles allows trainers to vary the learning activities and experiences they provide to their adult learners and this variation can, in turn, improve the learner's ability to not only learn but also retain the learning.

Peterson (2019) identifies that a significant difference between teaching children and teaching adults is the self-concept of adult learners. She identifies that adult learners are usually mature and self-confident enough to know their strengths and weaknesses and how they are able to best learn, including the most suitable environments and practices. This notion leads into the application of self-directed learning. In a situation of self-directed leaning, Peterson (2019) advises that learners can design their studies around their preferred learning style whether this is visual, auditory, or kinesthetic, also referred to as tactile learners.

Holmes (2014) discusses these learning styles and notes that visual learners prefer to be shown the learning content through graphs, diagrams, and illustrations. They rely on what the trainer is doing, and these learners learn most effectively when what to do is demonstrated or shown what something looks like. Auditory learners listen carefully to all sounds associated with the learning content. An Auditory learner pay attention to the sound of the trainer's voice and all of its subtle messages, and they will engage with the trainer and other participants with active participation in discussions. Tactile or kinesthetic learners need to physically do something to comprehend it. By performing activities for themselves, which can include trial and error, these learners will maximize their learning.

Smith and Dalton (2005) recognize that in a vocational education environment there are wide differences in learners, and developing training methodologies that are suited to these learners is likely to lead to more effective learning, greater satisfaction among learners, and stronger motivations to persevere in the learning activity. In order to accommodate varying learning styles, trainers need to be able to recognize the styles within their learner cohorts and provide a range of training activities to allow each learner to excel.

\subsection{High Risk Equipment}

Vocational education and training can involve learner development of competence in a range of plant and equipment operation depending on the course or qualification being undertaken. These can include any range of equipment from hand tools through to heavy vehicles to be operated on public roads. Within the range there are many specialized items of equipment relevant to specific industries such as agricultural equipment, mining equipment and aviation equipment, just to mention a few. Workplace Health and Safety Queensland (2019) identify that machinery and equipment have moving parts and the action of moving can have enough force in motion to cause injury to people. The use of machinery and equipment is a requirement for many occupational roles and common in most workplaces. Given the potential to cause harm, injury or fatality, the effectiveness of 
training is critical to the ongoing safe use of the equipment by the learner.

Many countries around the world have recognized that there are specific plant and equipment that are more likely than others to cause workplace injury or fatality. As an example, Safe Work Australia compiles the Work-related Traumatic Injury Fatalities data set. The data set provides national statistics on all workers and bystanders fatally injured at work (Safe Work Australia, 2020a). The Safe Work Australia (2020a) data highlights the mechanisms most likely to cause injury and/or fatality in Australian workplaces, with vehicle collision to be the most likely, followed by being hit by moving objects. These fatalities are associated with plant such as heavy vehicles/trucks and agricultural plant and equipment in the majority.

For the purposes of this discussion, crane operations will be used as an example of high risk plant. A crane is a type of machine used in many industries that is generally equipped with a hoist rope, wire ropes or chains, and sheaves. These machines are generally used both to lift and lower materials and to move them horizontally. Essentially designed to perform a range of lifting tasks, these machines are mainly used for lifting heavy things and transporting them to other places. There are a range of fixed (tower, bridge, gantry, portal boom, vessel-mounted) and mobile (slewing, non-slewing, vehicle loading) cranes (Safe Work Australia, 2020b). Further, a range of multi-purpose powered mobile plant, including multi-purpose tool carriers and telescopic handlers, may be also be classed as cranes in some operating configurations. Safe Work Australia (2020b) note that operating cranes is complex and dangerous, and workers must have the necessary skills and capabilities to safely operate these machines. Every year there are injuries and deaths from work involving cranes (Safe Work Australia, 2020b). Injury and fatality can occur in a number of ways whilst operating cranes such as through contact with power lines resulting in electrocution and crushing resulting from dropped loads or under the boom or hook, for example.

Use of high-risk plant in many countries requires the completion of a qualification in plant operations followed by licencing, normally endorsed by a government regulator. Using a mobile crane as an example, in the UK, to drive a mobile crane weighing between 3.5 and 7.5 tonnes a Category C1 Driving Licence is required and a Category C Licence if the crane is over 7.5 tonnes. Through Europe, currently each European Member State has its own rules for the professional competence and certification of crane operators (European Association of Abnormal transport and Mobile Cranes, 2020). These rules range from compulsory to optional and even to no rules at all. The European Association of Abnormal transport and Mobile Cranes is currently developing the ECOL which is an European Operator Licensing System aimed at the operators of mobile cranes. The training for the ECOL is delivered by training institutes and a precondition for taking part in an ECOL training and examination is that participants are at least 18 years old, and so adult learners, and hold of a valid EU class-C driving licence [truck driving licence]. Trucks are also considered to be high risk plant. In Australia a high-risk work licence is required for crane operations following the completion of training through a Registered Training Organization, through Australia's vocational Education and Training System.

Aside from the licencing rules in place in each country, generally each country has some training system in place for training operators in crane operations, mainly through a system of vocational education and training.

Health and Safety Executive (2020) identify that there are a number of inherent risks in moving, or high-risk equipment, and note that people can be struck and injured by moving parts of machinery or ejected material. They provide a range of other examples of risks including: Parts of the body can also be drawn in or trapped between rollers, belts and pulley drives; Sharp edges can cause cuts and severing injuries, sharp-pointed parts can cause stabbing or puncture the skin, and rough surface parts can cause friction or abrasion; People can be crushed, both between parts moving together or towards a fixed part of the machine, wall or other object, and two parts moving past one another can cause shearing; Parts of the machine, materials and emissions can be hot or cold enough to cause burns or scalds and electricity can cause electrical shock and burns. There are many ways incidents can occur in complex machine operation and each machine can have its own specific risks aside from general risks. Health and Safety Executive (2020) also highlights that injuries can further occur due to machinery becoming unreliable and developing faults, and likewise, when machines are used improperly through inexperience or lack of training. A machine in an unreliable state is unpredictable and an ability to deal with unexpected circumstances is a critical component of safe machine operation.

As such, training, and consequently learning, needs to go beyond the mechanical and operational aspects of the plant, such as which levers do what, to application of gained knowledge being used and contextualized such that a duty of care can be maintained to prevent injury and fatality.

In order to effectively train a learner to operate high risk plant and equipment, a range of adult learning principles need to be applied to develop the skills and knowledge to mechanically operate the machine, make adjustments to allow for the context, environment and task at hand, and maintain situational awareness and apply an ability to 
extrapolate skills and knowledge in a way that they are tied to maintaining safe and responsible practices.

\subsection{Application of Adult Learning Principles to High Risk Equipment Operations Training}

In applying Knowles principles of adult learning, trainers must recognize that adults must have a hand in the design and development of their learning experience. Watson (2105) outlines ways that this can be achieved, and this includes developing rapport with the learner to encourage questioning and consideration of concepts. The trainer must also show interest in the learner's thoughts and opinions which includes actively and carefully listening to any questions asked. Provision of both negative and positive feedback regular constructive and specific feedback allows learners to review their role and approach to their learning and provides an opportunity for them to review their goals and attained goal completion.

Training commences with leading the adult Learner toward inquiry before oversupplying them with facts. Trainers must also acknowledge the preferred learning style of the learner (Watson, 2015). Assessment tasks should set projects or tasks for the learner that reflect their interests and which they must complete.

In order to ensure that experience is at the root of the learning, trainers need to ascertain the Learner's personal, work and study related interests and past experiences, then assist them to make use of those experiences when problem-solving, reflecting and applying reasoning processes. Teaching practice needs to facilitate reflective learning opportunities, which also assist the learner to examine existing biases or habits derived from their life experiences (Fidishun, 2000). Watson (2015) notes that instead of offering memorization tasks, Trainers should develop projects and activities that encourage adult learners to explore the subject matter. The result being that learners gain experience. The learning process then allows adult learners to learn from their errors, often through trial and error practices, and master their skills sets through first-hand experience.

Adult learners need to be able to relate the learning to real world uses, gains and applications. If they cannot recognize how particular learning is going to apply to real world situations, then they are not likely to be excited about the learning process. Trainers are required to provide meaningful learning experiences that are clearly linked to personal, workplace and life goals. This requires the trainer to ask questions that motivate reflection, inquiry and further research (Watson, 2015). Adult learners must also be given the opportunity to absorb information, rather than merely committing it to memory. Allowing opportunity for absorption requires the trainer to create activities that allow adult learners to interact with specific tasks, such as simulations. In turn, learners will then store the information in their long-term memory, particularly through replication, repetition, and experience, thus building familiarity.

In order to facilitate relevancy, trainers should ask the Learner to reflect on what they expect to learn prior to undertaking the learning activity, on what they learnt following the learning experience, and the applications of what they have learnt, or how it will help them to meet their learning goals. Trainers can also provide some choice of practical project work by providing options to provide learning that is more likely to reflect the learner's interests and learning style.

Vocational education and training includes practical components to develop and demonstrate competence. Trainers should clearly explain their reasoning when making choices about assessments and should be explicit about how the learning is useful and applicable to the job and client group they are working with (Watson, 2015).

Training and assessment should promote active participation by allowing learner to try things rather than observing. Learners must be given the opportunity to practice and consolidate their skills. Cordiner (2020) concurs with highlighting that practicing skills in a controlled environment allows a learner to grow self-efficacy in new tasks that prepares them to act autonomously beyond the learning environment, such as their workplace. Cordiner notes that the more an adult learner can practice new skills, competencies or the application of knowledge, the more transformational impact the learning intervention will have.

Self-efficacy is the belief we have in our abilities and competencies (Chowdury, 2020). Chowdury refers to Albert Bandura (1977), a pioneer humanist and father of the concept of self-efficacy, who defined self-efficacy as "people's beliefs about their capabilities to produce designated levels of performance that exercise their influence over events that affect their lives", and goes on to outline that self-efficacy determines how we think and feel about ourselves. Self-efficacy should be considered a primary goal in training and assessment as it contributes to the value and retention of the training.

Trainers should develop and utilize training activities that focus on problem solving, involving identifying the problem, considering alternatives, decision making, and implementing a solution. Thompson (2019) suggests posing realistic questions and problems to encourage problem-solving is more effective than rote learning. To highlight this point, Thompson (2019) considers that we really do not expect a manager, in a workplace context, to 
ask an employee to recite a process from employee handbook by memory.

Narayan, Herrington, and Cochrane (2019) discuss the integration of a heutagogical approach in training design and note that effective training requires design of learning activities, tasks and a learning environment that encourage elements of learner participation, personalization, and productivity. Likewise, the trainer should aim to conduct learning activities in authentic contexts chosen by the learner to enable exploration and experimentation. Narayan et al. (2019) suggest that the heutagogical approach is underpinned by development and utilization of formative assessment events that encourage learner participation and reflection in authentic contexts such that the learning process is informed.

Blaschke (2012) advise that training design elements that support learner-centeredness in a heutagogical approach include utilization of flexible curriculum. The learner is instrumental in the development of flexible curriculum in a self-determined learning environment. They are instrumental in that they contribute to the learning pathway that will be followed to serve as mechanisms for helping learners make sense of course content, bring clarity to ideas, and promote individual and group reflection (Kenyon \& Hase, 2001; Eberle, 2009, cited in Blaschke, 2012). Blaschke (2012) continues with the notion that in heutagogy, negotiated and learner-defined assessment has been shown to improve the motivation of learners and their involvement in the learning process, as well as make learners feel less threatened by trainer control of their learning process. Negotiation can be incorporated into the assessment process through the use of learning contracts (Hase, 2009, cited in Blaschke, 2012). Blaschke (2012) also notes the need for assessment to include measurable forms of assessing understanding of content, including whether competence has been attained.

\subsection{Current Adult Learning Principles are not Necessarily Inclusive of a Sense of Responsibility}

In any workplace environment where someone is relying on an individual to be careful, and that reliance is, in the circumstances, reasonable, then it will generally be the case that the individual owes them a duty of care. Adult learners understand that they have a duty of care to themselves and others and strive to ensure they are able to meet this obligation.

Adults undertake training not only for their needs but also so that they can provide higher level care for others. As such, here we can introduce an extension adult learning principle, which can be referred to authology, derived from the translation of the English 'Responsible' to the Latin 'Author', as per Google Translate. The source of the word Author can also be related to the Latin words 'augeo', 'augere', 'auxi', and 'auctus' which have meanings including honor, promote, raise, increase, enlarge, and augment. The basis of the principle is that of an adult learner's need to be aware of and take responsibility for their actions in a workplace and ensure that their learning meets their social obligations to protect themselves and others. Authology then, is based on a tenet that adults have a sense of responsibility and duty of care which are rooted in the individuals' belief system. Duty of care in this context may be defined as a moral or legal obligation to ensure the safety or well-being of self and others. By extension, a duty of care exists when an individual's actions could reasonably be expected to affect other people.

The authological approach can be seen as an extension of andragogical and heutagogical approaches in that it facilitates an adult learner's ability to increase their sense of responsibility. The focus of the learning principle being on building the learner's needs to take responsibility for the welfare of others. The approach is therefore socially centric whilst maintaining andragogical principles. The learner is required to take responsibility for their own learning together with responsibility for the social implications of their own learning. The need to build one's capacity to provide effective duty of care may be seen as an additional pillar to those presented in Knowles initially identified key pillars of understanding adult learners.

Beaumont (2020) discusses the characteristics related to responsible adults and postulates taking responsibility for our choices provides the symmetry of reciprocal exchange and the basis for trust. Beaumont further presents that responsibility is a congruence between the actions we choose and our values. A number of specific characteristics are outlined, and these include an ability to inquire, investigate, seek, and embrace facts and truth. Adults have a need to ground their knowledge in fact and reality rather than simply believing what they are told. Through the training process, a sense of responsibility can be developed through the training practice. Authology requires a trainer to provide a contexts and environments where a learner can develop their sense of responsibility and duty of care. Training authologically requires the trainer to provide opportunity to develop responsible thinking and development in, using Beaumont's identified characteristics:

- Honesty

- Focusing thoughts and attention

- Thinking through alternatives and consequences 
- Clear and consistent thinking and expression

- Seeking out expertise

- Self-discipline

- Impulse control

- Openness to new ideas and information

- Willingness to accept blame for errors

- Rationality

- Able to make judgements on collected evidence

- Considering a variety of points-of-view

- Adaptation and flexibility

- Adjusting beliefs and actions to accommodate newly understood facts

- Autonomy

- Integrity

- Understanding that ideas, choices, and actions have consequences.

- Belief that effects and outcomes have causes.

- Internal Locus of Control

All of these characteristics are extremely important in the use of high-risk plant, which requires a high level of responsibility to ensure safe performance. Typically, any workplace health and safety system is built around the notion of duty of care and workers are indoctrinated into these principles as soon as they enter the workplace. Duty of care includes invoking responsibility. In high risk plant operations, the duty of care aspect of the work being undertaken is inflated on the basis that the worker has the increased potential to cause harm due to the nature of the equipment and work tasks performed. Particularly since failure to exercise care in operation of the specific plant may lead to foreseeable injury.

Beaumont (2020) outlines that responsibility requires autonomy and that adults can only feel accountable and be held accountable for the choices they make for themselves. Free choice, Beaumont suggests, is only possible when we are autonomous and notes the relationship between the two in that as autonomy increases, responsibility increases with it. In a training environment then, learners should be given the opportunity to work autonomously which ties in to heutagogical approaches. Autonomy grows with competence as does the perceived level of responsibility.

Where one person or agency imposes arbitrary rules in an attempt to control another, as can often happen in a training environment, those imposed rules reduce autonomy, and therefore reduce responsibility. Trainers in adult settings need to minimise imposing arbitrary rules and allow learners to recognise that their ideas, choices, and actions do matter and do have consequences. Beaumont (2020) recognises that treating adults like children by imposing arbitrary rules that destroy autonomy often encourages them to act like irresponsible children.

The core of acting responsibly requires considering the needs of others and the community, not only themselves (Beaumont, 2020) and this notion is the foundation of the concept of authological thinking. Further, a responsible adult learner will integrate experiences and information to act rationally, consistently, and reliably rather than unpredictably, inconsistently, irrationally, and erratically (Beaumont, 2020). Franzoso (2018) considers that responsibility is the ability to respond to situations and events and is a value we adopt in adulthood. Responsibility is adapted in adulthood as children are unable to as they have not yet developed discernment or their 'intellectual dimension'/logic. Acting responsibly and meeting duty of care obligations are central to adult learning and subsequent application of that learning in a workplace.

Returning to the crane example, learners should be given the opportunity to set up their own lifting scenarios and take responsibilities for all aspects of the lift. Initial lifts may be highly structured and controlled, however, ultimately the learner should be able to contrive their own lifts, perform the required preparation and complete the lift such that the lift is completed with regard for the safety of self, others and the community. Training and assessment activities of this nature require working autonomously, adapting to the task requirements and environment. As an example of the trainer role, where a learner expresses interest in managing a particular load with a crane, but then finds that he or she is having trouble understanding the correct configurations required, the trainer can recommend a similar load that is simpler to configure. McCombs (2020) identifies that the most 
effective strategies involve improving learners' abilities to identify and manage their emotions, appreciate and understand the perspectives of others, establish pro-social objectives, solve problems and use a variety of interpersonal skills to handle developmentally relevant tasks.

\section{Conclusion}

Effective training is critical in training scenarios where inadequate training can lead to injury or fatality, such as in high risk plant or equipment operations. Regardless of a Trainer's favored instructional approach, the goal is to prepare learners to undertake workplace activities safely and successfully. The skills and experience learners gain from self-determined learning are central in applying and maintaining the learning in an ongoing manner to a range of workplace contexts. Allowing learners to develop a sense of responsibility through training activities to subsequently meet obligations to a duty of care effectively should be considered a fundamental applicable adult learning principle. In a high-risk plant and equipment operations training environment, an authological approach should be integrated by trainers.

To train adults authologically, trainers need to discover how to help learners develop the ability to make appropriate choices and take responsible control the activities they perform. This can be achieved through guiding adult learners to understand their learning interests, dispositions to be active and autonomous learners and capacities or strengths in the required competency areas.

\section{References}

Adult Learning Australia. (2020). Adult learning principles. Retrieved from https://ala.asn.au/adult-learning/the-principles-of-adult-learning/

Bandura, A. (1997). Self-efficacy. The exercise of control. New York: W.H. Freeman and Company. Emory University, Division of Educational Studies, Information on Self-Efficacy: A Community of Scholars.

Beaumont, L. $\quad$ R. (2020). Responsibility. Retrieved from http://www.emotionalcompetency.com/responsibility.htm

Blaschke, L. M. (2012). Heutagogy and Lifelong Learning: A Review of Heutagogical Practice and Self-Determined Learning. https://doi.org/10.19173/irrodl.v13i1.1076

Chowdury, M. R. (2020). 4 Ways To Improve And Increase Self-Efficacy. Retrieved from https://positivepsychology.com/3-ways-build-self-efficacy/

Choy, S. \& Delahaye, B (2002). Andragogy in Vocational Education and Training: Learners' perspective. Retrieved from https://www.avetra.org.au/data/Conference_2002_pres./2_Sarojni_Choy.pdf

Collins, J. (2004). Education Techniques for Lifelong Learning. RadioGraphics, 24, 1483-1489. https://doi.org/10.1148/rg.245045020

Cordiner, S. (2020). The 8 Fundamental Principles Of Adult Learning That Every Course Creator \& Training Professional Should Know. Retrieved from https://sarahcordiner.com/the-8-fundamental-principles-of-adu/

Davis, L. (2018). Heutagogy Explained: Self-Determined Learning in Education. Retrieved from https://www.schoology.com/blog/heutagogy-explained-self-determined-learning-education

European Association of Abnormal transport and Mobile Cranes. (2020). European Crane Operators Licence. Retrieved from https://ecol-esta.eu/

Fidishun, D. (2000). Andragogy and technology: Integrating adult learning theory as we teach with technology. Paper presented at the Instructional Technology Conference, Pennsylvania.

Franzoso, E. (2018). The Difference between Responsibility and Accountability. Retrieved from https://www.elisabettafranzoso.com/articles/2017/12/2/redefining-responsibility

Hase, S., \& Kenyon, C. (2000). From andragogy to heutagogy. Retrieved from http://www.avetra.org.au/data/Conference_2001_pres./54_Stewart_Hase_Chris_Kenyon_paper.pdf

Health and Safety Executive. (2020). Why is machinery safety important? Retrieved from https://www.hse.gov.uk/toolbox/machinery/safety.htm

Holmes, T. (2014). 5 Principles for Teaching Adult Learners. Retrieved from https://generalassemb.ly/blog/principles-teaching-adults/

Knowles, M. (1970). The modern practice of adult education: Andragogy versus pedagogy. Chicago: Follet Publishing Company. 
Knowles, M. (1990). The adult learner: A neglected species (4th ed.). Houston, Texas, Gulf.

McCombs, B. (2020). Developing Responsible and Autonomous Learners: A Key to Motivating Students. Retrieved from https://www.apa.org/education/k12/learners

Mowson, R. (2018). Adult Learning Principles and Styles: Area's to Consider When Delivering Training. Retrieved from https://www.clearhorizon.com.au/all-blog-posts/adult-learning-principles-and-styles-areasto-consider-when-delivering-training.aspx

Narayan, V., Herrington, J., \& Cochrane, T. (2019). Design principles for heutagogical learning: Implementing student-determined learning with mobile and social media tools. Australasian Journal of Educational Technology, 35(3). https://doi.org/10.14742/ajet.3941

Peterson, D. (2019). 5 Principles for the Teacher of Adults. Retrieved from https://www.thoughtco.com/principles-for-the-teacher-of-adults-31638

Rogers, C. R. (1969). Freedom to learn. Columbus, Ohio: Merrill.

Safe Work Australia. (2020a). Work-related injury fatalities - Key WHS statistics Australia 2019. Retrieved from https://www.safeworkaustralia.gov.au/book/work-related-injury-fatalities-key-whs-statistics-australia-2019

Safe Work Australia. (2020b). Cranes. Retrieved from https://www.safeworkaustralia.gov.au/cranes

Skills You Need. (2020). Learning Styles. Retrieved from https://www.skillsyouneed.com/learn/learning-styles.html

Smith, P., \& Dalton, J. (2005). Accommodating learning styles: Relevance and good practice in VET. National Centre for Vocational Education Research (NCVER): Adelaide, SA.

Thompson, S. (2019). 7 Adult Learning Principles Every Online Educator Should Know. Retrieved from https://www.newrow.com/7-adult-learning-principles-every-online-educator-should-know/

Watson, B. (2015). Adult learning theory and the six principles of adult learning. Retrieved from https://brucedwatson.wordpress.com/2015/05/05/adult-learning-theory-and-the-six-principles-of-adult-learn ing/

Workplace Health and Safety Queensland. (2019). Guide to machinery and equipment safety. State of Queensland.

\section{Copyrights}

Copyright for this article is retained by the author(s), with first publication rights granted to the journal.

This is an open-access article distributed under the terms and conditions of the Creative Commons Attribution license (http://creativecommons.org/licenses/by/4.0/). 